\title{
Plasma Nitriding of Surface Mo-Enriched Sintered Iron
}

\author{
T. Bendo, ${ }^{1}$ H. C. Pavanati, ${ }^{2}$ A. N. Klein,, ${ }^{1}$ A. E. Martinelli, ${ }^{3}$ and A. M. Maliska ${ }^{1}$ \\ ${ }^{1}$ LABMAT, Departamento de Engenharia Mecânica, Universidade Federal de Santa Catarina, 88040-900 Florianópolis, SC, Brazil \\ ${ }^{2}$ IF-SC, Departamento Acadêmico de Metal-Mecânica, Instituto Federal de Santa Catarina, 88020-300 Florianópolis, SC, Brazil \\ ${ }^{3}$ UFRN, Departamento de Engenharia de Materiais, Universidade Federal do Rio Grande do Norte, Lagoa Nova Campus, \\ 59072-970 Natal, RN, Brazil
}

Correspondence should be addressed to T. Bendo, tatianabendo@yahoo.com.br

Received 27 April 2011; Accepted 5 June 2011

Academic Editors: Y. Hiraoka and R. Rodríguez

Copyright ( $) 2011$ T. Bendo et al. This is an open access article distributed under the Creative Commons Attribution License, which permits unrestricted use, distribution, and reproduction in any medium, provided the original work is properly cited.

Plain iron samples produced by powder metallurgy were submitted to a single thermal cycle involving plasma-assisted sintering and simultaneous surface alloying with Mo followed by nitriding using a plasma reactor. The microstructural characterization of the samples was carried out by optical and scanning electron microscopy in addition to X-ray diffraction. Microhardness tests were also performed. EDX line profiles of the concentration of Mo from the surface to the bulk of the sintered samples showed that the alloying element diffused down to depths of about $25 \mu \mathrm{m}$ under the sintering conditions applied. A significant increase in microhardness was observed for samples enriched with Mo and subsequently nitrided. This behavior was attributed to the precipitation of nitrides and the presence of Mo in solid solution.

\section{Introduction}

Ferrous powder metallurgy products have been increasingly used as a result of their low production costs. An approach to improve the mechanical properties of sintered iron is the addition of alloying elements. The preparation of ferrous alloys by powder metallurgy can be carried out using three alloying techniques:

(a) compaction of feedstocks produced by mixing elemental powders,

(b) compaction of iron powder mixed with master alloys or carrier alloys,

(c) compaction of prealloyed powders, in which each particle has the composition of the required alloy.

The compaction of feedstocks produced by mixing elemental powders is advantageous in most cases (depending on the alloy system) because of the relatively high compressibility of feedstocks, which results in high green density values. However, the addition of some alloying elements, including Mo and $\mathrm{W}$, impairs the homogenization of feedstocks as a consequence of their low-diffusion coefficients in iron, thus requiring elevated sintering temperatures. In such cases, prealloyed powders can be used. However, due to their usually high hardness, high-compaction pressures are necessary in order to obtain adequate green densities. Other alloying elements, for example, $\mathrm{Si}, \mathrm{Mn}, \mathrm{Cr}$, and $\mathrm{Ti}$, are difficult to protect against oxidation in industrial processes, as a consequence of the high stability of their corresponding oxides. In this case, highly pure sintering atmospheres regarding the chemical potential of oxygen $[1,2]$ are necessary. In such cases, the use of prealloyed powders is advantageous. Once in solution in the iron matrix, the chemical activity of alloying elements is reduced, which limits their susceptibility to oxidation. It is also possible to achieve good protection against oxidation by adding the alloying elements to the powder mixture (feedstock) as compounds (carbides or nitrides), in the form of binary ferroalloys such as ferrosilicon, ferromanganese, and ferrochromium, or even as master alloys $[1,2]$. In all these situations, the equilibrium of the metal with its corresponding oxide takes place at higher chemical potentials compared to that of the pure metal, and, therefore, highly pure treatment atmospheres are not required. Prealloyed powders are advantageous for oxidation protection. In addition, their homogenization can be easier accomplished compared to powder mixtures. On the contrary, they usually depict low 


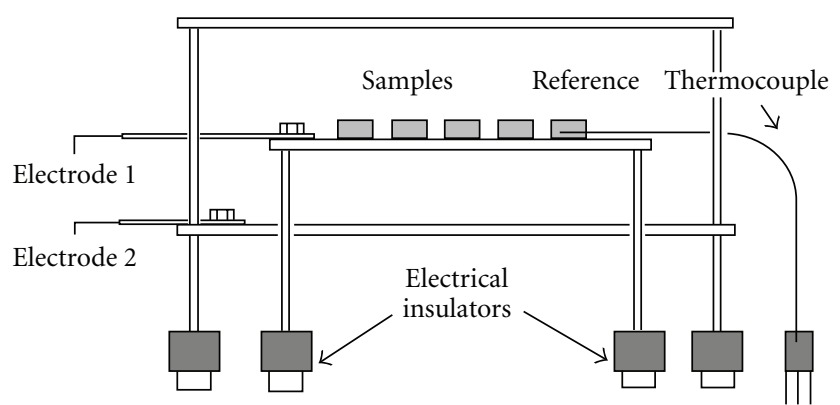

FIGURE 1: schematic representation of the sample holder used in the combined thermochemical treatment (plasma sintering, superficial Mo-alloying, and nitriding).

compressibility as a result of their high hardness. The use of master alloys, binary compounds, or other carrier alloys can be a solution to reduce the reactivity of the elements with oxygen and to improve the homogenization kinetics during sintering. However, also in this case, one must expect low compressibility $[1,2]$.

In several applications of sintered metallurgical materials, failure occurs on the surface of the component by fatigue fracture, wear, or corrosion. Therefore, surface properties play a relevant role on the performance of devices. For such applications, alloying the bulk of the sintered component is not necessary at all. Surface alloying is a cost-efficient way to tailor the material to specific service conditions and, furthermore, produce functionally graded materials.

Attempts to modify the chemistry of the surface of plain iron compacts during sintering in a plasma reactor have been recently reported $[3,4]$. The chemical composition of the surface is enriched with atoms of alloying elements, intentionally sputtered from a suitable cathode of a plasma DC reactor. When energetic species bombard the cathode, atoms from the cathode itself are sputtered into the gaseous phase. Such atoms move towards the surface of the sample, which is the anode of the system, where they are finally deposited. As the sample is heated, the deposited atoms gain mobility and diffuse, alloying shallow areas of the sample. As a consequence, the properties of the surface and near surface areas of the sintered component differ from those of its bulk.

Some of the alloying elements used in recent enrichment studies carried out for sintered iron components included $\mathrm{Cr}$ and Mo [3-5]. It is expected that after the sample is enriched with alloying elements during plasma sintering, the composition of the surface enables the formation of hard and stable compounds, such as nitrides, carbides, or carbonitrides by subsequent thermochemical treatments [6-8]. In this approach, thermochemical treatments can be performed after the sintering step, using the same plasma reactor and thermal cycle.

In the present work, plain iron samples were enriched with Mo during plasma sintering aiming at surface alloying and characterized. It has been previously demonstrated that it is possible to obtain homogeneous superficial layers enriched with Mo down to depths of about $25 \mu \mathrm{m}$ during plasma assisted sintering [4]. The role of Mo in the micro- structural transformations that occur during plasma nitriding of sintered Fe samples enriched with Mo was investigated.

\section{Experimental and Materials}

$6.0 \times 6.0 \times 2.5 \mathrm{~mm}^{3}$ pellets were produced by pressing AHC-100.29 water-atomized Fe powder (Höganäs Brasil Ltda). The particle size of the powder ranged from 30 and $200 \mu \mathrm{m}$ and its mean particle size was around $100 \mu \mathrm{m}$. The powder was mixed with $0.8 \mathrm{wt} . \%$ zinc stearate and uniaxially double action pressed under $600 \mathrm{MPa}$. Sintering with simultaneous surface enrichment and subsequent nitriding were performed in a single plasma reactor. Two holders to place the samples in the reactor were designed and assembled. They had the same dimensions but different compositions (Figure 1). The first holder was made of TZM alloy containing approximately $99.4 \mathrm{wt}$.\% of Mo to place the samples onto the grounded electrode (electrode 1, anode configuration). The holder for the nitriding step was made of AISI 1020 steel. The sample was placed onto the negatively biased electrode (electrode 2, cathode configuration).

In order to establish basis for comparison, an additional set of samples was sintered onto an AISI 1020 steel support (to avoid Mo enrichment) and subsequently nitrided under the same processing conditions. For all plasma treatments, the anode was grounded and the cathode negatively biased using a DC pulsed power source capable of varying the cathode voltage from $300 \mathrm{~V}$ to $700 \mathrm{~V}$, the mean current from $20 \mathrm{~A}$ to $30 \mathrm{~A}$, and the switched on $\left(t_{\mathrm{on}}\right)$ pulse period from 10 to $240 \mu \mathrm{s}$. A reference sample (sintered iron) was symmetrically placed on the sample holder and used to measure the temperature. A type $\mathrm{K}$ thermocouple, coated with Inconel and electrically insulated with $\mathrm{Al}_{2} \mathrm{O}_{3}$, was inserted $5 \mathrm{~mm}$ into the reference sample. Delubing was carried out before sintering and surface enrichment in the same plasma reactor under hydrogen (99.99\% pure) at $1.3 \mathrm{~Pa}$ (0.01 Torr) at $400^{\circ} \mathrm{C}$ during $30 \mathrm{~min}$. After that, the samples were plasma sintered with simultaneous Mo enrichment in a gas mixture of $80 \% \mathrm{Ar}\left(99.99 \%\right.$ pure) and $20 \% \mathrm{H}_{2}$ (99.99\% pure), flowing at $4.0 \times 10^{-6} \mathrm{~m}^{3} \mathrm{~s}^{-1}(240 \mathrm{sccm})$. All samples were sintered at $1150^{\circ} \mathrm{C}$ for $60 \mathrm{~min}$ at the output voltage of $500 \mathrm{~V}$. The pulse length of the power source was fixed at $180 \mu \mathrm{s}$. The pressure system was maintained at about $2.6 \times 10^{2} \mathrm{~Pa}$ (2.0 Torr).

All plain-Fe and Mo-enriched samples were plasma nitrided. Nearly pure Mo samples (TZM alloy) were also nitrided for comparison purposes. The nitriding time was set at $120 \mathrm{~min}$. Temperature and gas mixture parameters were evaluated. The plasma DC equipment used in this work consisted of a hybrid furnace (or hybrid-plasma reactor) whose chamber, or processing environment, is equipped with two electrodes to generate a DC plasma and electrical resistances to heat the furnace. The electrical heaters are used to adjust the correct treatment temperature, since plasma heating is not enough to reach usual sintering or nitriding temperatures [9]. The parameters used in the plasma nitriding cycles are summarized in Table 1. 
TABLE 1: Plasma nitriding parameters.

\begin{tabular}{lcc}
\hline Temperature & $540^{\circ} \mathrm{C}$ & $450^{\circ} \mathrm{C}$ \\
\hline Gas & $\begin{array}{c}75 \% \mathrm{~N}_{2}+25 \% \mathrm{H}_{2} \\
\text { Composition }\end{array}$ & $\begin{array}{c}75 \% \mathrm{~N}_{2}+95 \% \mathrm{H}_{2} \\
5 \% \mathrm{~N}_{2}+95 \% \mathrm{H}_{2}\end{array}$ \\
\hline $\begin{array}{l}\text { Working } \\
\text { Pressure }\end{array}$ & $\begin{array}{c}4.0 \times 10^{2} \mathrm{~Pa} \\
(3.0 \mathrm{Torr})\end{array}$ & $\begin{array}{c}4.0 \times 10^{2} \mathrm{~Pa} \\
(3.0 \mathrm{Torr})\end{array}$ \\
\hline $\begin{array}{l}\text { Source Output } \\
\text { Voltage }\end{array}$ & $500 \mathrm{~V}$ & $500 \mathrm{~V}$ \\
\hline$T_{\text {on }}$ (time on $)$ & $180 \mu \mathrm{s}$ & $180 \mu \mathrm{s}$ \\
\hline Holding Time & $120 \mathrm{~min}$ & $120 \mathrm{~min}$ \\
\hline
\end{tabular}

The crystalline phases present in the composition of the surface layer of the nitrided samples were evaluated by Xray diffraction (XRD) using $\mathrm{Cu} \mathrm{K} \alpha$ radiation. The samples were then cross-sectioned top to bottom, cold mounted in resin to assure edge retention, ground, polished, and etched in 2\% nital. A Leica DM 4000 M optical microscope was used to identify the presence of nitrides and to visualize the Moenriched layer of the samples both in the as-sintered state and after nitriding. Microhardness profiles were made on the cross-sections of the samples using a Shimadzu HMV 2000 tester.

\section{Results and Discussion}

The cross-section of a Mo-enriched sintered sample is shown in Figure 2(a). It is possible to observe a contrast corresponding to the Mo-enriched layer. As the Mo atoms diffuse into the sample, the concentration of the alloying element changed from maximum, at the surface, to null, at depths of 25 to $30 \mu \mathrm{m}$ into the bulk of the sample (Figure 2(b)).

A significant compositional variation is noticed from the surface to few micrometers into the enriched region. The content of Mo is constant (around 3.0 to 3.5 wt.\%) until a depth of $15 \mu \mathrm{m}$. From that point on, there is a sharp fall in the Mo content until a depth of $25 \mu \mathrm{m}$. This behavior was also observed in other studies [4] and is related to the stabilization of the $\alpha$-Fe phase at $1150^{\circ} \mathrm{C}$, as predicted by the Fe-Mo phase diagram [10]. The Mo concentration profile, the depth of the enriched layer, and its uniformity are similar for all samples.

Optical micrographs of cross-sectioned samples of nitrided $\mathrm{Fe}$ are shown in Figure 3. Samples nitrided at higher temperature $\left(540^{\circ} \mathrm{C}\right)$ show a deeper diffusion layer compared to that of samples nitrided at lower temperature $\left(450^{\circ} \mathrm{C}\right)$, because the nitriding mechanisms are essentially diffusive [11-13]. With respect to the concentration of nitrogen in the gas mixture, samples nitrided under $75 \%$ nitrogen exhibited thicker compound layers, consisting of $\varepsilon-\mathrm{Fe}_{2-3} \mathrm{~N}$ and $\gamma^{\prime}$ $\mathrm{Fe}_{4} \mathrm{~N}$, compared to those nitrided under $5 \%$ nitrogen. It was observed that the temperature variation $\left(450\right.$ to $\left.540^{\circ} \mathrm{C}\right)$ did not significantly affect the microstructure of these samples. Their microhardness profiles are shown in Figure 4. The hardness of the nitride layers was around $200 \mathrm{HV}$, which is typical of diffusion layers in nitrided plain iron. However, this value is relatively low for compound or white layers. The hardness of compound layers is typically around $700 \mathrm{HV}$ for steel or nitrided plain iron $[14,15]$. However, due to the limited thickness of the white layer obtained in this work and instrumental restrictions, indentations for microhardness tests could not be done. As a consequence, it is not possible to state the accurate microhardness value of the compound layers portrayed herein. Nevertheless, based on previous studies carried out using similar materials and processing parameters, the microhardness of the compounds layers can be safely assumed to be around $700 \mathrm{HV}[14,15]$.

The optical micrographs of Mo-enriched and nitrided samples are shown in Figure 5. Samples enriched and nitrided in a nitrogen-poor atmosphere (Figures 5(a) and 5(b)) depicted superficial regions free of precipitates visible by optical microscopy. Below this region, the presence of fine precipitates with noncircular morphologies and needleshaped can be observed. These structures are similar to that of nitrides precipitated in plain iron. The content of Mo in this region is very low, indicating that these precipitates are actually iron nitrides. The top layer does not show visible precipitates. This region could be formed by a compound layer of molybdenum nitrides and iron nitrides, or else by a $\alpha$-Fe layer with nitrogen in solid solution. The Mo-enriched samples nitrided in a nitrogen-rich atmosphere (Figures 5(c) and 5(d)) depict distinct microstructure. Sample E75TA presented a dark layer precipitated between two regions, that is, the outer layer that appears to be a white layer and the nitrogen diffusion zone (below the dark layer). In sample E75TB, the superficial layer grows as short and elongate needles towards the bulk of the sample (substrate). Below the Mo-enriched region, precipitates form a new phase beginning at the grain boundaries. The formation of the darkened layer begins within these precipitates, as can be seen in sample E75TA (Figure 5(c)).

The optical micrograph shown in Figure 6 reveals the early stages of the precipitation of the dark layer, seen in sample E75TA (Figure 5(c)). It is believed that this phase is very rich in nitrogen. This darkened microstructure is similar to the precipitation of expanded austenite $\left(y_{\mathrm{n}}\right)[16,17]$ which is a metastable phase containing high concentrations of nitrogen [16-18].

The development of this phase can be related to the presence of molybdenum. In the molybdenum enriched region, nitrogen diffuses fast, because of the high solubility of molybdenum in the ferritic matrix. Moreover, molybdenum atoms are relatively large and distort the crystal lattice of iron, facilitating the diffusion of nitrogen in this region [19]. When nitrogen diffuses through the molybdenum enriched region, it encounters the ferritic matrix. There, its coefficient of diffusion decreases, because the diffusion coefficient of $\mathrm{N}$ in iron is lower than in the Mo-enriched region. Therefore, large amounts of nitrogen in solid solution accumulate in the region placed between the compound layer, rich in nitrogen, and the diffusion zone, in which molybdenum is not present. In other words, it is believed that the dark region consists of expanded austenite which precipitation due to the presence of molybdenum, which increases the concentration of nitrogen in this region, favouring the transformation of ferrite into austenite. 


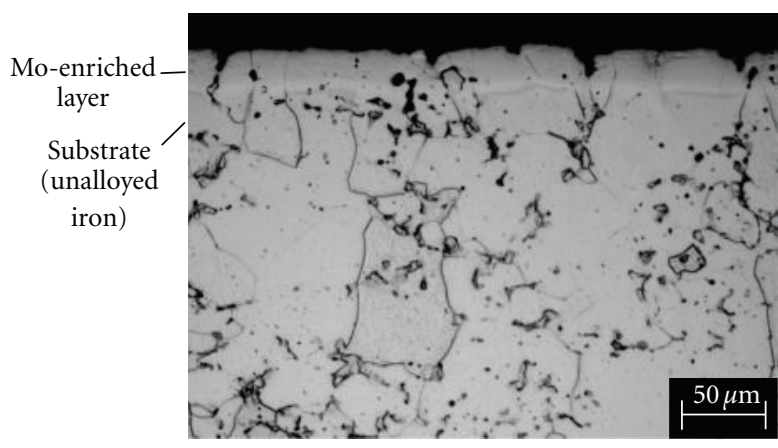

(a)

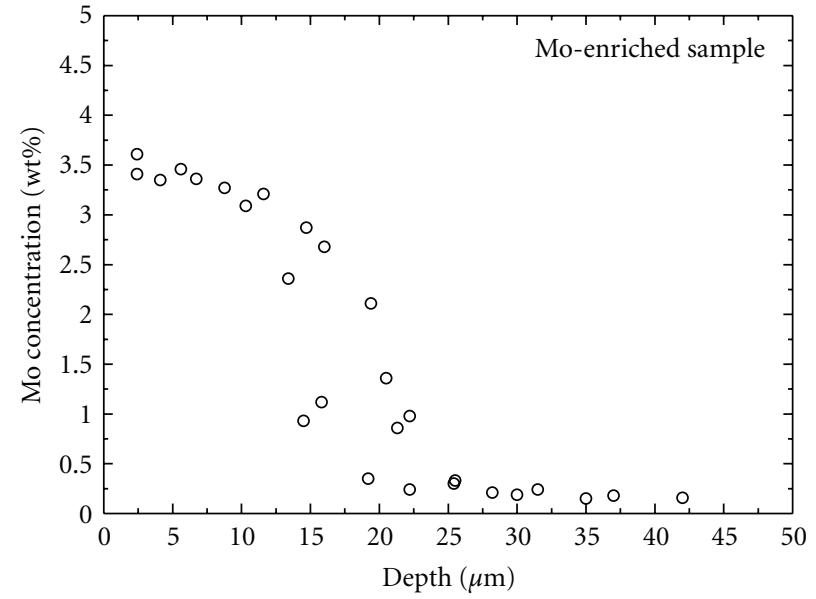

(b)

Figure 2: (a) Optical micrograph and (b) line profile of molybdenum concentration of the cross-section of a sample sintered at $1150^{\circ} \mathrm{C}$ and enriched with Mo.

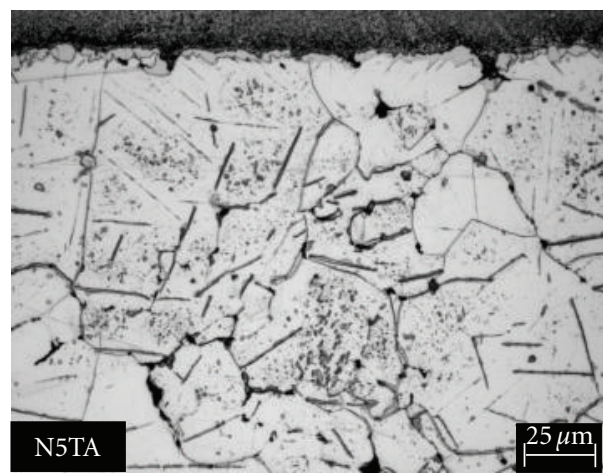

(a)

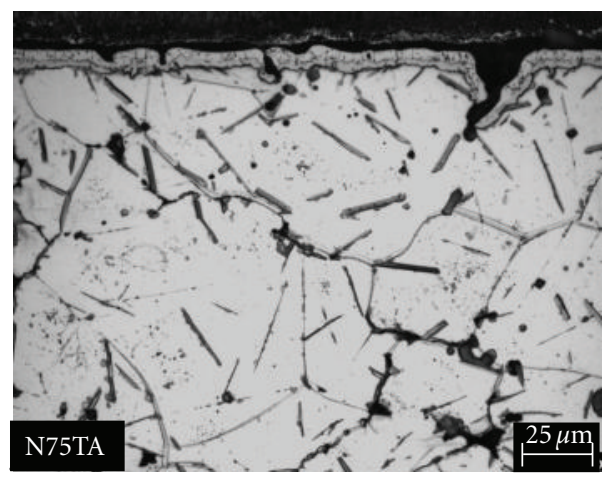

(c)

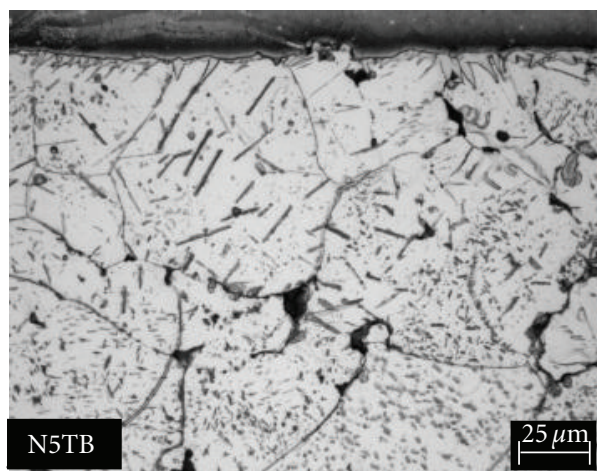

(b)

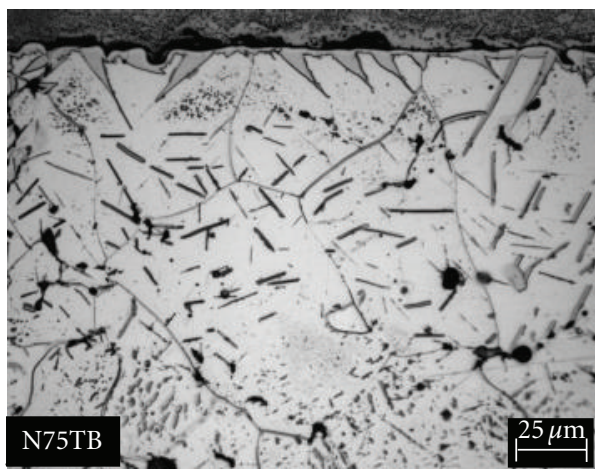

(d)

FIgURE 3: Optical micrographs of the cross-sections of plasma nitrided plain iron samples: (a) N5TA nitrided under 5 vol.\% of $\mathrm{N}_{2}$ and $540^{\circ} \mathrm{C}$; (b) N5TB nitrided under 5 vol\% of $\mathrm{N}_{2}$ and $450^{\circ} \mathrm{C}$; (c) N75TA nitrided under 75 vol. $\%$ of $\mathrm{N}_{2}$ and $540^{\circ} \mathrm{C}$; (d) $\mathrm{N} 75 \mathrm{~TB}$ nitrided under 75 vol. $\%$ of $\mathrm{N}_{2}$ and $450^{\circ} \mathrm{C}$.

From XRD analyses (Figure 7) of the enriched and nitrided samples, both $\varepsilon-\mathrm{Fe}_{2-3} \mathrm{~N}$ and $\gamma^{\prime}-\mathrm{Fe}_{4} \mathrm{~N}$ were identified in the samples nitrided under 75 vol.\% of $\mathrm{N}_{2}$. This suggested that the surface layer of these samples (E75TA and E75TB) is indeed a compound layer. For samples nitrided under 5 vol. $\%$ of $\mathrm{N}_{2}$, only $\alpha$-Fe peaks were identified.
Considering samples E5TA and E5TB, it is believed that nitrogen may be present forming an interstitial solid solution. There is also the possibility that very fine precipitates were formed, but are not visible under optical microscopy and cannot be directed detected by XRD. This assumption can be confirmed by the widening of the $\alpha$-Fe peaks in XRD. 


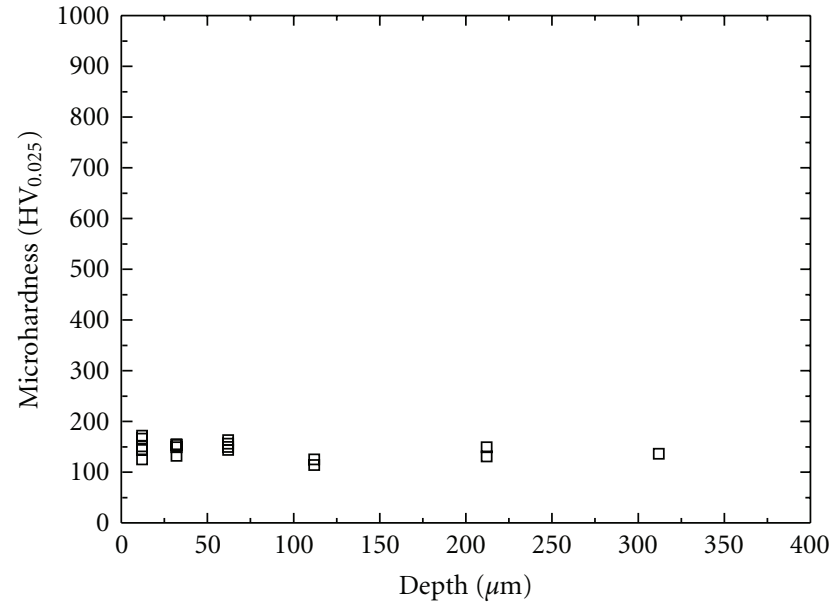

(a) N5TA nitrided at $540^{\circ} \mathrm{C}$

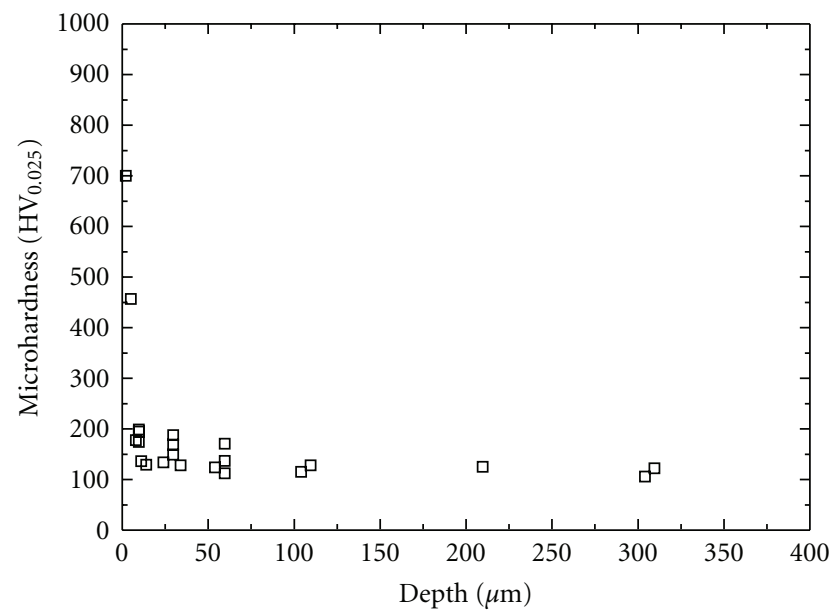

(c) N75TA nitrided at $540^{\circ} \mathrm{C}$

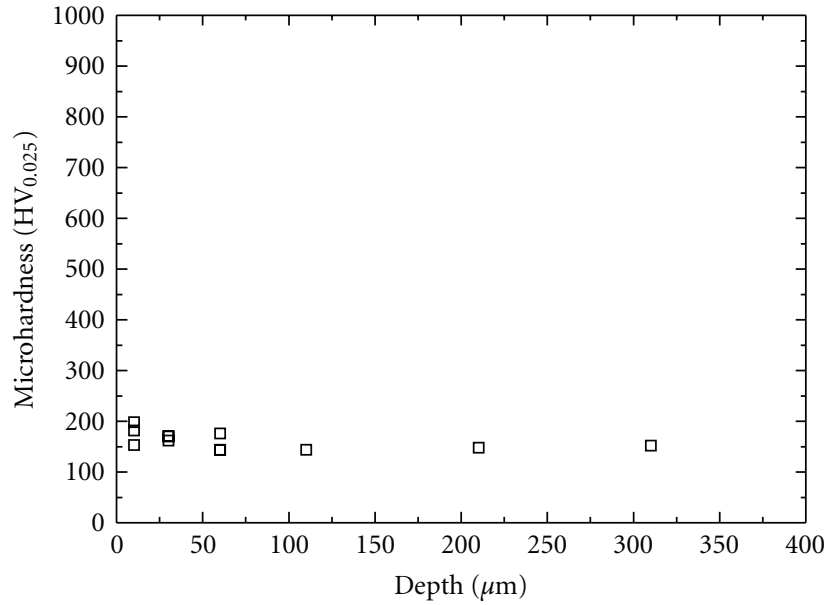

(b) $\mathrm{N} 5 \mathrm{~TB}$ nitrided at $450^{\circ} \mathrm{C}$

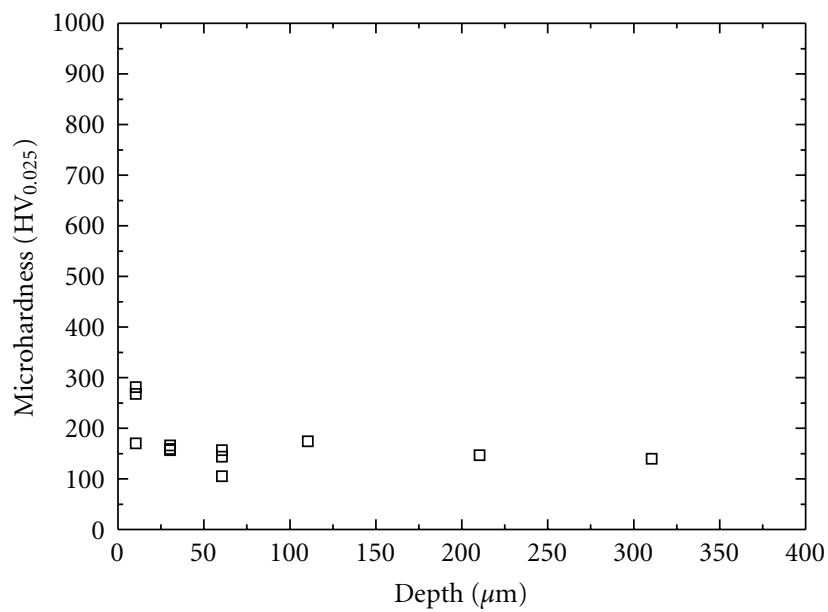

(d) $\mathrm{N} 75 \mathrm{~TB}$ nitrided at $450^{\circ} \mathrm{C}$

Figure 4: Microhardness profiles of the cross-section of sintered and plasma-nitrided plain iron samples.

The fact that the molybdenum nitrides are not detected by XRD analysis can be related to the low concentration of Mo in this region, between 3.0 and $3.5 \mathrm{wt} \%$.

The microhardness profile of the Mo-enriched and plasma-nitrided samples are presented in Figure 8. Samples E5TA and E5TB showed maximum hardness values of $700 \mathrm{HV}$ and $300 \mathrm{HV}$, respectively. These values are higher than those observed from plain iron plasma-nitrided samples thermally treated under the same conditions, as previously demonstrated (Figure 4). In the XRD patterns of samples E5TA and E5TB (Figure 7), only $\alpha$-Fe was indentified. In this case, the increase in hardness can be assigned to the presence of nitrogen in solid solution in the ferritic matrix and the existence of very fine precipitates dispersed in the matrix. When the compound layer, visible in E75TA and E75TB samples, shown in Figures 5(c) and 5(d), respectively, is formed, the values of the microhardness reached $1100 \mathrm{HV}$ and $950 \mathrm{HV}$, respectively. These values are higher than those of plain iron nitrided samples and can therefore be attributed to the presence of molybdenum. It is believed that in the enriched and nitrided samples, molybdenum nitrides or mixed $\mathrm{Fe}-\mathrm{Mo}$ nitrides may be present in the enriched region, but they are not detected due to the low concentration of Mo.

To confirm the precipitation of MoN in the conditions and parameters used in this study, plain TZM samples (99.4 wt.\% Mo) were nitrided. Their XRD patterns (Figure 9) did not indicate the presence of MoN. Only Mo was detected. This result indicates that the nitriding conditions established for this work did not result in the formation of MoN.

The presence of molybdenum nitrides is not observed in the Mo-enriched and nitrided samples. The nitrided layers of these samples were harder than those of plain iron samples. From that, it can be said that the mutual interaction between Fe and N, with small amounts of Mo, accounts for the increase in hardness of the nitrided layer. Small amounts of Mo, between 3.0 and $3.5 \mathrm{wt} . \%$ are enough for a significant increase in hardness after nitriding. It is believed that in the enriched and nitrided samples, high concentrations of nitrogen are present forming an interstitial solid solution in the Mo-enriched layer, distorting the crystalline lattice of this region and causing compressive stresses which increase hardness. 


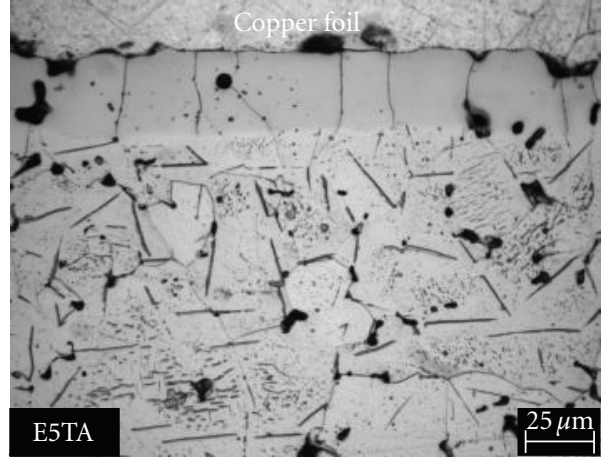

(a)

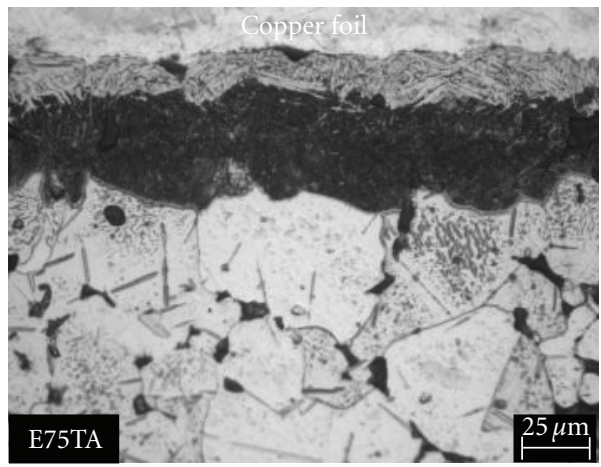

(c)

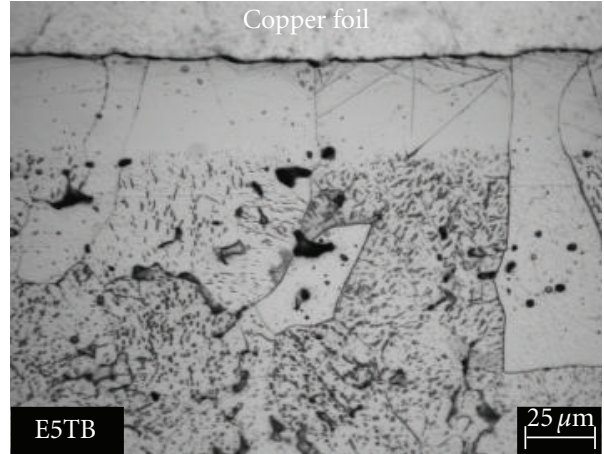

(b)

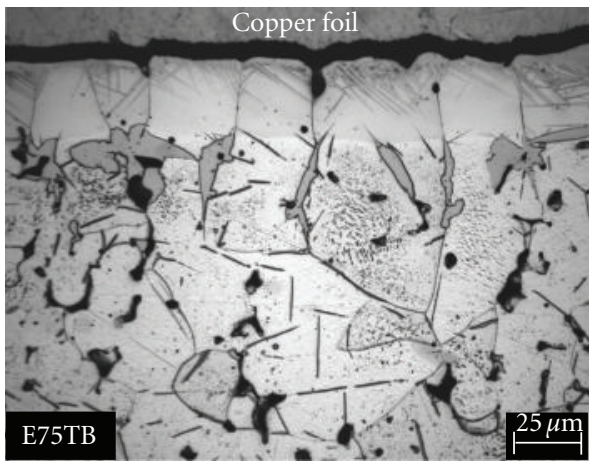

(d)

Figure 5: Optical cross-sectional micrographs of iron samples enriched with Mo and nitrided: (a) E5TA nitrided under 5 vol.\% of $\mathrm{N}_{2}$ and $540^{\circ} \mathrm{C}$; (b) E5TB nitrided under 5 vol. $\%$ of $\mathrm{N}_{2}$ and $450^{\circ} \mathrm{C}$; (c) E75TA nitrided under 75 vol. $\%$ of $\mathrm{N}_{2}$ and $540^{\circ} \mathrm{C}$; (d) E75TB nitrided at 75 vol. $\%$ of $\mathrm{N}_{2}$ and $450^{\circ} \mathrm{C}$.

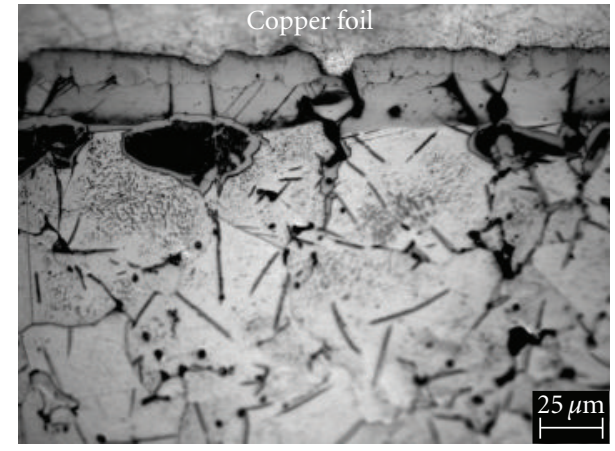

Figure 6: Optical cross-sectional micrograph of iron sample enriched with Mo and nitrided at intermediary temperature $\left(\sim 500^{\circ} \mathrm{C}\right)$ under 75 vol. $\%$ of $\mathrm{N}_{2}$.

\section{Conclusions}

The results presented herein show that the combined interaction between iron and molybdenum considerably increased the hardness of the nitrided layers. This effect is attributed to the formation of mixed Fe-Mo nitrides. Nitrided unalloyed iron as well as nitrided molybdenum showed lower hardness values. It is believed that a little amount of Mo in iron is sufficient to significantly enhance the hardness of the com-

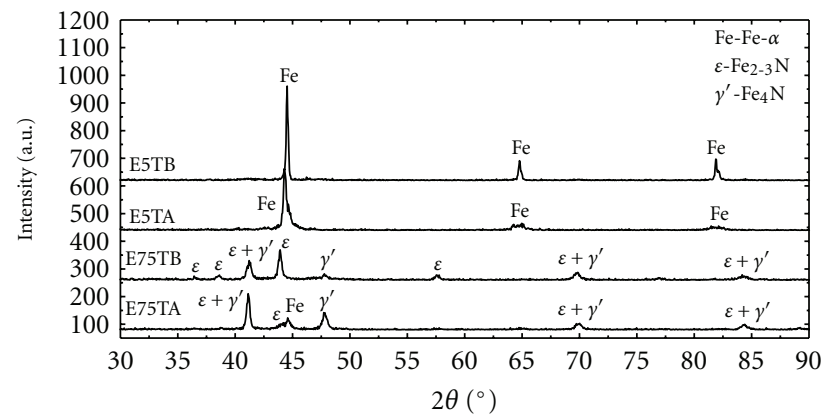

FIGURE 7: XRD patterns of the surfaces of iron samples enriched with $\mathrm{Mo}$ and plasma-nitrided. $\mathcal{\varepsilon}-\mathrm{Fe}_{2-3} \mathrm{~N}, \gamma^{\prime}-\mathrm{Fe}_{4} \mathrm{~N}$, and $\mathrm{Fe}-\alpha$ phases identified in the figure.

pound layer. Moreover, it was also observed that the presence of Mo increased the solubility of nitrogen in the Mo-enriched layer, resulting, among other effects, in solid solution hardening.

\section{Acknowledgments}

This work was financially supported by CAPES, CNPq, and Embraco S.A. research grants. 


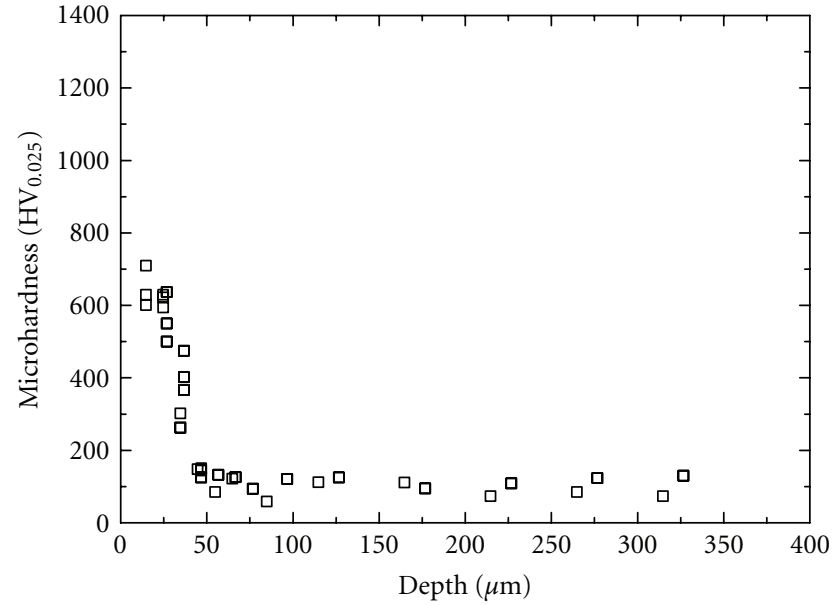

(a) E5TA nitrided at $540^{\circ} \mathrm{C}$

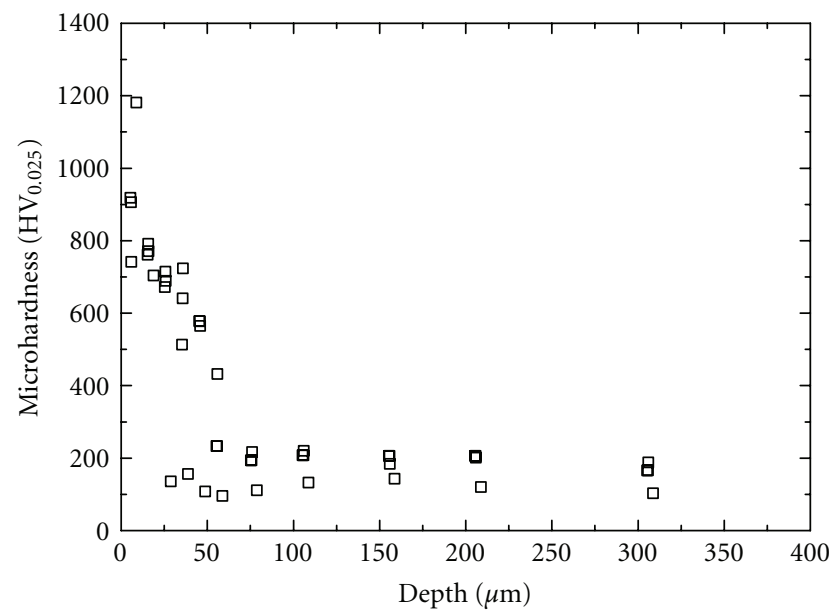

(c) E75TA nitrided at $540^{\circ} \mathrm{C}$

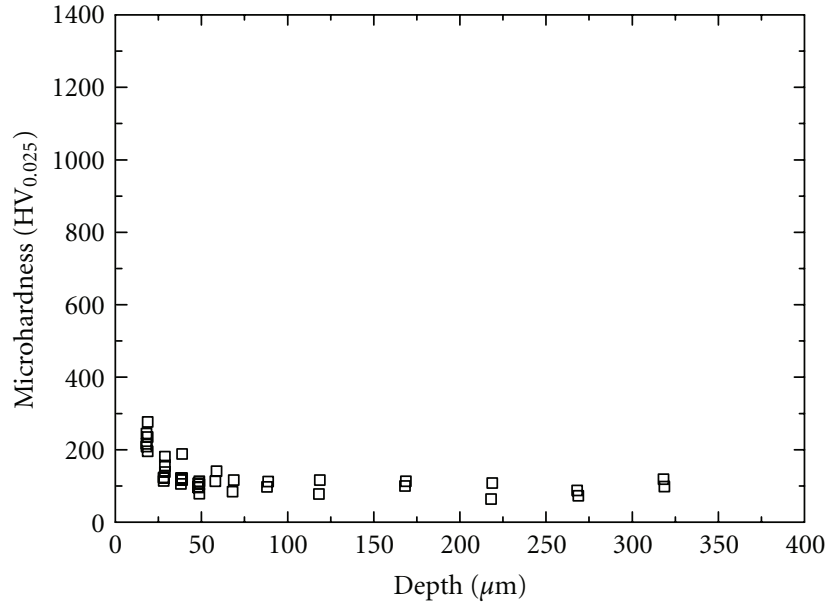

(b) E5TB nitrided at $450^{\circ} \mathrm{C}$

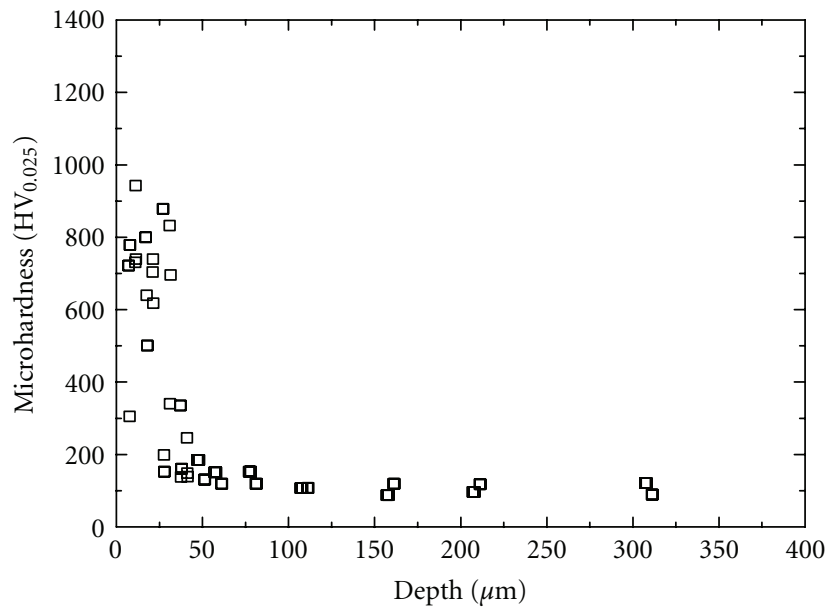

(d) E75TB nitrided at $450^{\circ} \mathrm{C}$

FIGURE 8: Microhardness profiles of the cross-section of iron samples enriched with Mo and plasma-nitrided.

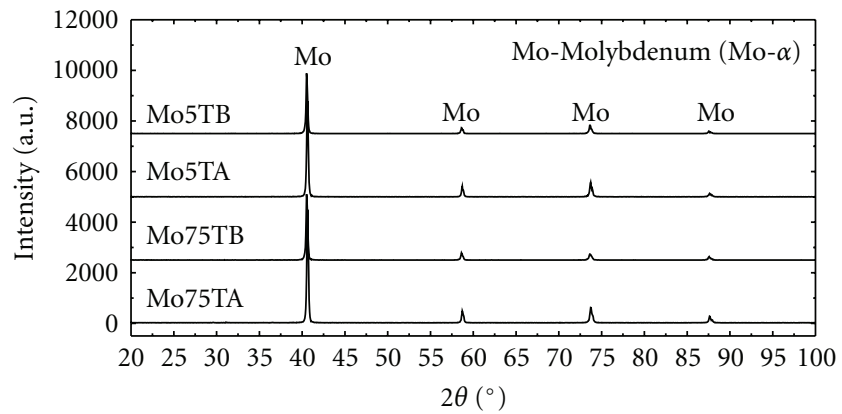

FIGURE 9: XRD patterns of the surfaces of plasma-nitrided TZM samples. Mo5TA nitrided at $540^{\circ} \mathrm{C}$; Mo5TB nitrided at $450^{\circ} \mathrm{C}$; Mo75TA nitrided at $540^{\circ} \mathrm{C}$ and Mo75TB nitrided at $450^{\circ} \mathrm{C}$.

\section{References}

[1] A. N. Klein, R. Oberacker, and F. Thuemmler, "High-strength Si-Mn alloyed sintered steels-sinterability and homogenization," Powder Metallurgy International, vol. 17, no. 2, pp. 7174, 1985.
[2] F. Thümmler and R. Oberacker, Introduction to Powder Metallurgy, The Institute of Materials, Cambridge, UK, 1993.

[3] X. Jiang, A. Jiahe, X. Xie, and Z. Xu, "Multi-element Ni-CrMo-Cu surface alloyed layer on steel using a double glow plasma process," Surface and Coatings Technology, vol. 168, no. 2-3, pp. 142-147, 2003.

[4] H. C. Pavanati, J. M. Lourenço, A. M. Maliska, A. N. Klein, and J. L. R. Muzart, "Ferrite stabilization induced by molybdenum enrichment in the surface of unalloyed iron sintered in an abnormal glow discharge," Applied Surface Science, vol. 253, no. 23, pp. 9105-9111, 2007.

[5] H. C. Pavanati, A. M. Maliska, A. N. Klein, and J. L. R. Muzart, "Sintering unalloyed iron in abnormal glow discharge with superficial chromium enrichment," Materials Science and Engineering A, vol. 392, no. 1-2, pp. 313-319, 2005.

[6] A. M. Maliska, A. M. Oliveira, A. N. Klein, and J. L. R. Muzart, "Surface porosity sealing effect of plasma nitrocarburizing on sintered unalloyed iron," Surface and Coatings Technology, vol. 141, no. 2-3, pp. 128-134, 2001.

[7] M. U. Devi and O. N. Mohanty, "Plasma-nitriding of tool steels for combined percussive impact and rolling fatigue wear applications," Surface and Coatings Technology, vol. 107, no. 1, pp. 55-64, 1998. 
[8] Z. Xu, X. Liu, P. Zhang, Y. Zhang, G. Zhang, and Z. He, "Double glow plasma surface alloying and plasma nitriding," Surface and Coatings Technology, vol. 201, pp. 4822-4825, 2007.

[9] G. Hammes, C. Binder, L. L. Perin, H. C. Pavanati, and A. N. Klein, "Sinterização de ferro puro por plasma com enriquecimento superficial simultâneo de Mo com amostras posicionadas no cátodo, ânodo ou em potencial flutuante," in Proceedings of the $61^{\circ}$ Congresso Anual da ABM, Rio de Janeiro, Brazil, 2006.

[10] M. Hansen, Constitution of Binary Alloys, McGraw-Hill, New York, NY, USA, 1958.

[11] B. Edenhofer, "Physical and metallurgical aspects of ionitriding," Heat Treatment of Metals, no. 2, pp. 59-67, 1974.

[12] E. Metin and T. Inal, "Formation and growth of iron nitrides during ion-nitriding," Journal of Materials Science, vol. 22, no. 8, pp. 2783-2788, 1987.

[13] E. J. Miola, S. D. Souza, and M. D. Olzon, "Systematic study on influence of the nitriding parameters on pure iron superficial layer properties," Surface and Coatings Technology, vol. 167, no. 1, pp. 33-40, 2003.

[14] Y. Gao, X. P. Guo, and R. Wei, "Rapid nitriding of pure iron by thermal plasma jet irradiation," Surface and Coatings Technology, vol. 201, no. 6, pp. 2829-2834, 2006.

[15] L. C. Gontijo, R. Machado, E. J. Miola, L. C. Casteletti, and P. A. P. Nascente, "Characterization of plasma-nitrided iron by XRD, SEM and XPS," Surface and Coatings Technology, vol. 183, no. 1, pp. 10-17, 2004.

[16] T. Czerwiec, N. Renevier, and H. Michel, "Low-temperature plasma-assisted nitriding," Surface and Coatings Technology, vol. 131, pp. 267-277, 2000.

[17] L. C. Gontijo, R. Machado, E. J. Miola, L. C. Casteletti, N. G. Alcântara, and P. A. P. Nascente, "Study of the S phase formed on plasma-nitrided AISI 316L stainless steel," Materials Science and Engineering A, vol. 431, no. 1-2, pp. 315-321, 2006.

[18] T. Inoue, Y. Hiraoka, E. Sukedai, M. Nagae, and J. Takada, "Hardening behavior of dilute Mo-Ti alloys by two-step heat treatment," International Journal of Refractory Metals and Hard Materials, vol. 25, pp. 138-143, 2007.

[19] S. Mandl, J. W. Gerlach, and B. Rauschenbach, "Nitride formation in transition metals during high fluence-high temperature implantation," Surface and Coatings Technology, vol. 200, pp. 584-588, 2005. 

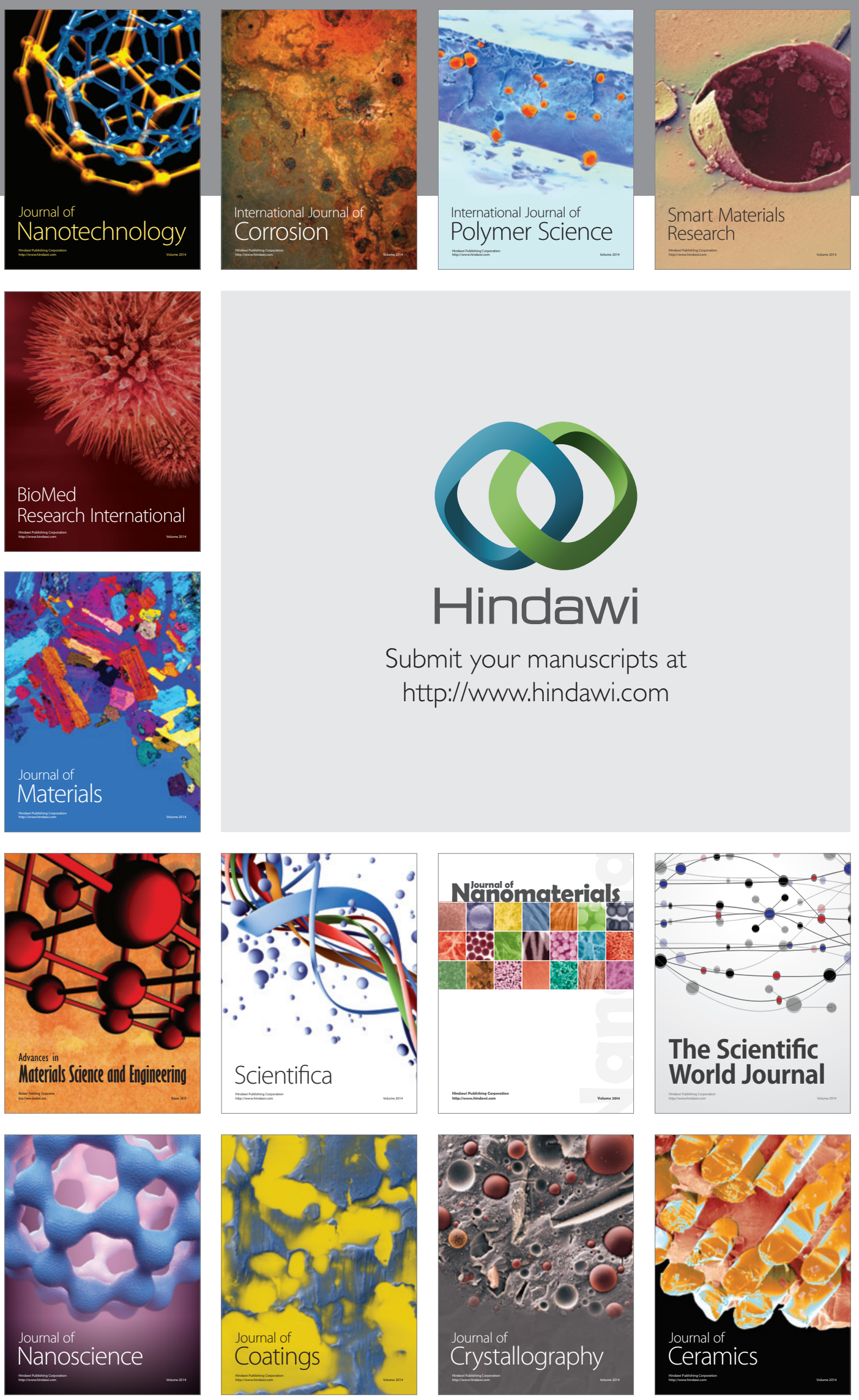

The Scientific World Journal

Submit your manuscripts at

http://www.hindawi.com

\section{World Journal}

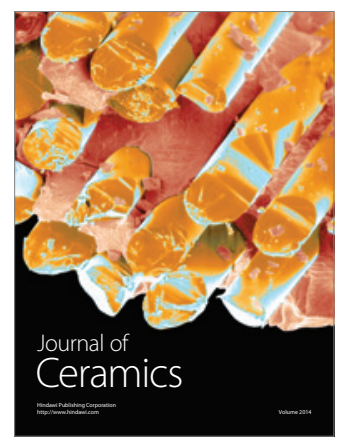

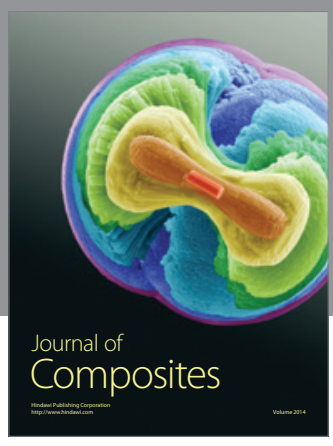
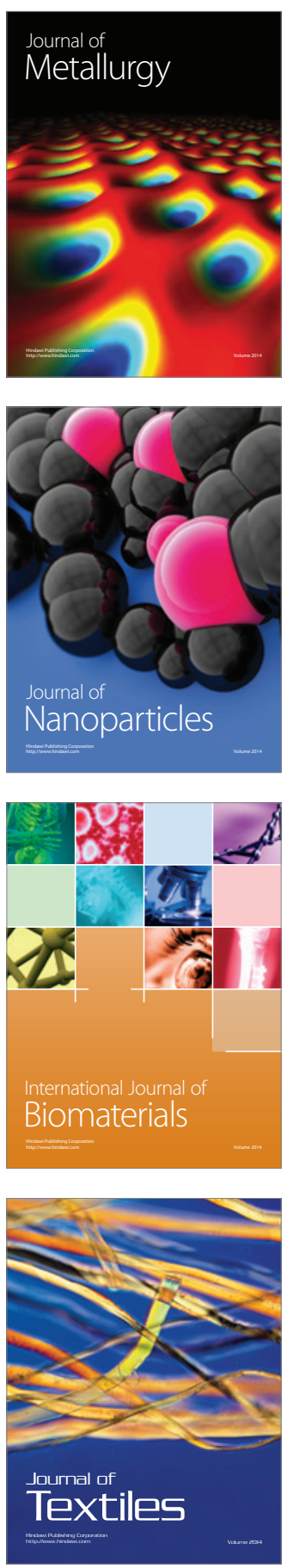